\title{
Editorial
}

\section{Volumen 10, Número 2}

Psicología Conocimiento y Sociedad

Con la publicación de este nuevo número alcanzamos el aumento de la periodicidad de la publicación, lo cual fue uno de los objetivos propuestos en el plan de trabajo (2019-2020).

La conmemoración de los diez años de PCS nos pareció el momento propicio para dar este importante paso, mediante el cual anunciamos el pasaje de una frecuencia semestral a una cuatrimestral. Se publicarán tres números cada año, en los meses de marzo, agosto y noviembre. Esto supone un aumento considerable en el esfuerzo que el Equipo Editorial realiza, es un importante desafío que estamos dispuestos a asumir en pos del crecimiento de nuestro proyecto editorial. Para autoras y autores supondrá una disminución en los tiempos de espera desde que el manuscrito es aceptado hasta su publicación.

Uno de los elementos que hace posible el pasaje a la frecuencia cuatrimestral es el incremento en la cantidad de manuscritos recibidos, lo cual evidencia la consolidación de PCS y la valoración que ha alcanzado en la comunidad académica que se siente convocada y nos elige como canal de difusión del conocimiento original que produce.

El número que aquí presentamos está integrado por ocho artículos, seis de los cuales forman parte de la sección Artículos Originales y dos de la sección Revisiones.

La sección artículos originales se inicia con el artículo de Amanda Dias Dourado y Paulo César Zambroni-de-Souza investigadores de la Universidade Federal Da Paraíba (Brasil). En su artículo Motivação e trabalho: investigação sobre a experiência 
dos jovens no primeiro emprego desde un abordaje cualitativo se aproximan a la motivación de los jóvenes para comenzar a trabajar en comparación con la motivación para permanecer en el trabajo. Participaron del estudio 30 jóvenes de entre 18 y 23 año, que se encontraban en su primera experiencia laboral. Entre los principales resultados resaltan que para la mayoría de los jóvenes la motivación inicial para trabajar se vincula a la remuneración, experiencia y poder ayudar a la familia, en tanto su motivación para continuar trabajando se asocia con el logro de la independencia y el éxito profesional.

El artículo de Patricia Mónica Dubini de la Universidad Nacional de Córdoba, titulado La vida entre dos mundos. El papel del otro en la constitución subjetiva de jóvenes en contexto vulnerabilidad social, indaga mediante relatos de vida, sobre la constitución subjetiva de diez jóvenes entre 18 y 22 años de edad privados de libertad en Córdoba, Argentina. En el análisis, plantea el trascendental papel del otro en los procesos de constitución subjetiva: por un lado, la ausencia o presencia ominosa deja marcas que produce dificultades en el proceso de subjetivación; y por otro lado, la presencia que ofrece sostén se constituye en fuente de reconocimiento, habilita procesos de cambio que liberan de la mera repetición de la historia y abre la posibilidad de horizontes desiderativos.

Renan Monteiro, Tatiana Monteiro, Vitória Maciel, Fabio Masotti, Igor Freitas y Juarid Candido de la Universidade Federal de Mato Grosso (Brasil) presentan el artículo Essa vou postar: Explorando as relações entre narcisismo, uso do instragram e a moderaçao da autoestima. En el mismo se explora el rol predictor del narcisismo, mediado por la autoestima con respecto a la utilización de la red social Instagram. Los resultados indican un impacto positivo del narcisismo y negativo por parte de la autoestima en la utilización de Instagram, operacionalizada mediante el número de fotos e historias publicadas, el tiempo de edición y la importancia atribuida al feedback recibido. Los autores mencionan que la base de la relación entre estas variables 
puede corresponder a un mecanismo de compensación por bajos niveles de autoestima.

Gustavo Montenegro e Ivana Karina Schroeder de la Universidad Católica de Córdoba, (Argentina) en su artículo Dimensiones del pensamiento sistémico aplicado: un estudio de casos múltiple desde la perspectiva de sistemas complejos y el aprendizaje organizacional desarrollan un estudio de casos en pequeñas y medianas organizaciones de la ciudad de Córdoba. Concluyen que el pensamiento sistémico incide en los procesos de tratamiento de problemas, en el logro de mejoras, e innovaciones entre otros aspectos. Este se manifiesta como un emergente interaccional y contextual más que como una competencia individual en las organizaciones estudiadas.

Telmo Mota Ronzani, Bárbara Any Bianchi Bottaro de Andrade, Henrique Pinto Gomide y Fernando Antonio Basile Colugnati de la Universidade Federal de Juiz de Fora (Brasil) en la investigación Prevalence and Treatment of Tobacco Use Among Patients Being Treated for Mental Disorders, estudian las características de consumo de tabaco en personas con trastornos mentales graves. Encuentran una alta frecuencia de consumo de tabaco que acompaña el tratamiento farmacológico e incide en la salud, destacando los fracasos en la deshabituación del consumo en esta población. Advierten que este problema queda mayormente invisibilizado por los profesionales de la salud lo que repercute en la atención de estas personas. Remarcan la necesidad de intervenciones en la limitación del tabaquismo que acompañen el tratamiento de los trastornos mentales, permitiendo atender la salud de estos sujetos de manera integral.

El artículo de Marina Edith Tomasini sobre ¿Qué mueve a las jóvenes a participar? Activismo de género y construcción de identidades en estudiantes de escuelas secundarias de Córdoba, Argentina, enfoca un asunto de actualidad y debate en los estudios sobre juventud y feminismo en América Latina. La autora, en base a un 
diseño cualitativo, analiza los motivos que llevan a las jóvenes cordobesas (Argentina) a concurrir a las marchas, los temas que les preocupan y las demandas que plantean entorno a la construcción identitaria y las transformaciones en las relaciones sexogenéricas. La autora propone discutir el devenir identitario de estas jóvenes considerando tres procesos interrelacionados: agencia, intersubjetividad y conciencia. En artículo propuesto por Rodrigo Braicovich de CONICET (Argentina) con el título Ontogénesis del sentido de justicia. El criterio de igualdad analizado desde la psicología del desarrollo presenta un relevamiento de la emergencia del criterio de igualdad en escenarios intersubjetivos desde la Psicología del Desarrollo. Despliega una descripción crítica de modelos unitarios y duales a la vez que analiza los criterios de reciprocidad, igualdad y mérito en la ontogénesis del sentido de justicia. Finalmente sugiere la necesidad de incorporar en nuevas investigaciones otros criterios como pueden ser los de de propiedad y territorialidad.

Por último, encontramos el artículo de Catalina Luz Pizarro Poblete y Adriana Elizabeth Espinoza Soto, de la Universidad de Chile. Tratamientos Basados en Mindfulness en la Población Infanto-Juvenil con Sintomatología Ansiosa. Una Revisión Sistemática busca explorar los posibles efectos de intervenciones basadas en el mindfulness (o atención plena en español) en población infanto-juvenil con sintomatología o trastorno de ansiedad. Algunas de las conclusiones más relevantes refieren a diversas debilidades metodológicas en la literatura analizada, así como a la poca cantidad de trabajos publicados con esta población específica. Las mismas representan importantes condicionantes al momento de establecer el nivel de eficacia de estos tratamientos, las autoras incentivan la realización de más estudios en este importante campo.

Esperamos encuentren en este nuevo número artículos de interés, agradecemos especialmente a autoras y autores por elegir a PCS para dar a conocer el fruto de sus actividades de investigación y a todas/os las/os revisores que con sus rigurosos 
aportes han contribuido al proceso de mejora de la calidad académica de cada artículo que compone este número.

Karina Curione

ORCID ID: 0000-0002-4069-5615

Editora

Pilar Bacci

ORCID ID: 0000-0002-6611-1905

Co-Editora

Por Comité Editorial Javier Romano ORCID ID: 0000-0002-5594-9104

Mónica Da Silva ORCID ID: 0000-0003-2522-4716

Victor Ortuño ORCID ID: 0000-0002-9523-0874

Alejandra López-Gómez ORCID ID 0000-0001-9975-7297

doi: http://dx.doi.org/10.26864/PCS.v10.n2.ed 